\title{
Revamping the Knitwear Cluster in Tirupur - A Bold initiative towards Sustainable Development
}

\author{
*M. Prabhakar Christopher David, Assistant Professor, Department of Business Administration, Vels \\ Institute of Science, Technology \& Advanced Studies (VISTAS), Chennai. \\ Dr. S. Rajarajeswari, Assistant Professor and Head, Department of Business Administration, Sri \\ Meenakshi Govt Arts College for Women (A), Madurai
}

\begin{abstract}
The rapid growth of the knitwear industry in Tirupur has led to the depletion and contamination of the ground and surface water in the region. The study outlines the pollutant effects of the knitwear production process and the efforts of the industry and the government to curtail them. Despite appreciable efforts taken, the problems still seem to persist. This article suggests measures to revamp the knitwear cluster through application of greener practices which would lead to the development of this knitwear industry in a more sustainable way.
\end{abstract}

Keywords: Wet process, Common Effluent treatment plants, $R \& D$, common brand

\section{Introduction}

Tirupur a small town in Tamilnadu during the decades after India's independence, shot to fame after 1985 as a busy exporting town of hosiery products to most of the developed countries of the world. Not only the town has the pride of being called 'dollar town' and the 'town that never sleeps', it was applauded as the 'town of export excellence' by the EXIM policy 2002-07. Tirupur's hosiery industry initially produced only inner garments that too only white in colour. Till the late 1960s, this industry produced mainly grey and bleached vests called banians. In 1968, other items, mainly underwear began to be manufactured. From 1980 onwards, some of the entrepreneurs also began to produce T-shirts for exports. With their focus on diversification and quality control and with the strength of direct connections with foreign buyers the cluster is now into multi product cotton knitwear and produces T-shirts, cardigans, jerseys, pullovers, ladies' blouses, skirts, trousers, sportswear and industrial wear.

Tirupur is in a dry, water-scarce region, and the rapid expansion of the textile industry has taken place in an unplanned manner, with no associated development of supporting infrastructure or institutional capacity. As a result, the growth has led to the depletion of groundwater reserves and a serious deterioration in environmental quality of both surface and ground water.

\section{The knitwear production process in Tirupur}

The production process in Tirupur comprises of four operations organized around different firms. They are:

i. Knitting of cotton yarn to make grey fabric, 
ii. Bleaching \& dyeing of grey fabric,

iii. Fabrication of garments and

iv. Printing $\&$ finishing.

Of all the four processes mentioned above, the bleaching and dyeing is the most pollutant. Bleaching the grey colour of the knit fabric is essential for the dyeing process. This process involves mixing of bleaching powder in water through which the grey fabric is made to pass. There are various other chemicals used as well. Almost sixty percent of the bleached fabric requires dyeing and it accounts for almost 10 to 15 percent of the cost of finished garments [1]. The most essential requirements for dyeing are getting the correct shade on the fabric as per the buyer's specification and its colour fastness. Any deviation may lead to rejection of the lot and entail losses for the dyers. The skills of dyeing master who mixes various base dyes to get the correct shade are therefore crucial in the process. The most important machinery used in the process is a simple winch machine. Other supporting equipments required are a boiler and a big tank with an open furnace. In almost two hours of time, the dye-stuff is completely absorbed by the cloth which is then rinsed with fresh water, and treated with a few other ingredients and detergents. The complete cycle time is 6 to 10 hours [2]. The quality of dyeing is also determined by the hardness of water used. The textile wet processing units (bleaching, dyeing) are the major consumers of water as well as major contributors to pollution. The discharge of salts in effluent from the dyeing factories in Tirupur has led to large-scale environmental degradation.

Figure 1: Cotton fabric production and associated water pollutants

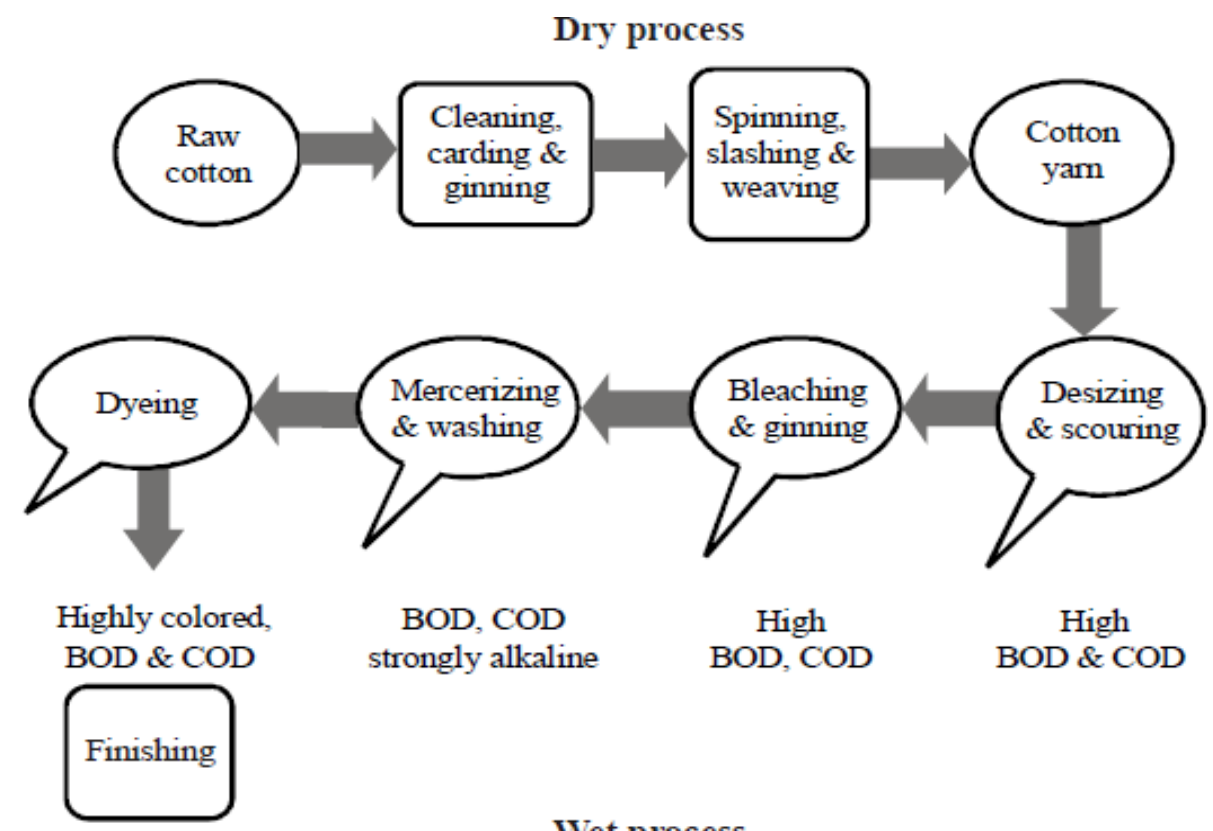

Wet process

Source:

http://cpcb.nic.in/openpdffile.php?id=UmVwb3J0RmlsZXMvNDEwXzE0OTU3MTQzMzZfbWVkaW

FwaG90bzQ1MjIucGRm 
Textile wastewaters are characterized by extreme fluctuations in parameters such as chemical oxygen demand (COD), biochemical oxygen demand (BOD), $\mathrm{pH}$, color and salinity. The composition of the wastewater depends on the different organic- based compounds, chemicals and dyes used in the dry and wet-processing. During dyeing process, it has been estimated that the losses of un-fixed dyes to the environment can reach 10-50\% [3]. One of the most difficult tasks confronted by the wastewater treatment plants of textile industries is the removal of the color, mainly because dyes and pigments are designed to resist biodegradation, such that they remain in the environment for a long period of time.

Table 2: Wastewater generation processes and their nature

\begin{tabular}{|c|l|}
\hline Process & \multicolumn{1}{|c|}{ Nature } \\
\hline Sizing & High in BOD, COD \\
\hline De-sizing & High in BOD, COD, Dissolved Solids \\
\hline Bleaching & High alkalinity, Suspended Solids \\
\hline Mercerizing & High PH, Dissolved Solids \\
\hline Dyeing & Strong Color, High BOD, Dissolved Solids \\
\hline Printing & Color, High BOD, Suspended Solids \\
\hline
\end{tabular}

\section{Source:}

http://cpcb.nic.in/openpdffile.php?id=UmVwb3J0RmlsZXMvNDEwXzE0OTU3MTQzMz ZfbWVkaWFwaG90bzQ1MjIucGRm

In Tirupur, most of the bleaching and dyeing units in are located in clusters along the banks of the river Noyyal. The partially treated and untreated effluent from dyeing units was discharged into this river till 2006, which resulted in significant increase in TDS and chloride level in the Noyyal River and Orathupalayam dam located across the river. In 2006, the High Court has directed the dyeing units to install zero liquid discharge (ZLD) plant and to stop discharging of effluent into the river[4]. The problem was so serious that the Madras High Court also ordered for the closure of all dyeing and bleaching units that failed to comply with ZLD in 2011[5]. The court also directed the State Pollution Control Board to initiate criminal prosecution against units that failed to rectify defects leading to pollution [6]. This move caused lot of turbulence within the cluster. The industry struggled since majority of the units in Tirupur were small in size and found it extremely difficult to install effluent treatment plants due to its high cost. But soon there was a solution, knitwear units joined hands to installing Common Effluent Treatment Plants (CETP). These CETPs consisted of physicochemical, biological treatment, RO plant and reject management systems to achieve ZLD. Soon Individual 
Effluent Treatment Plants (IETP) were also set up. Now by complying with the court order, Tirupur has become the first textile cluster in India to achieve Zero Liquid Discharge.[7] The diagram below shows the stretches of Noyyal river passing through Tiruppur and the location of CETPs that exists along the Noyyal river. It can be observed that all CETPs \& IETPs are located in between Point A \&F.

Fig 1: Location of CETPs and IETPs along the river Noyyal

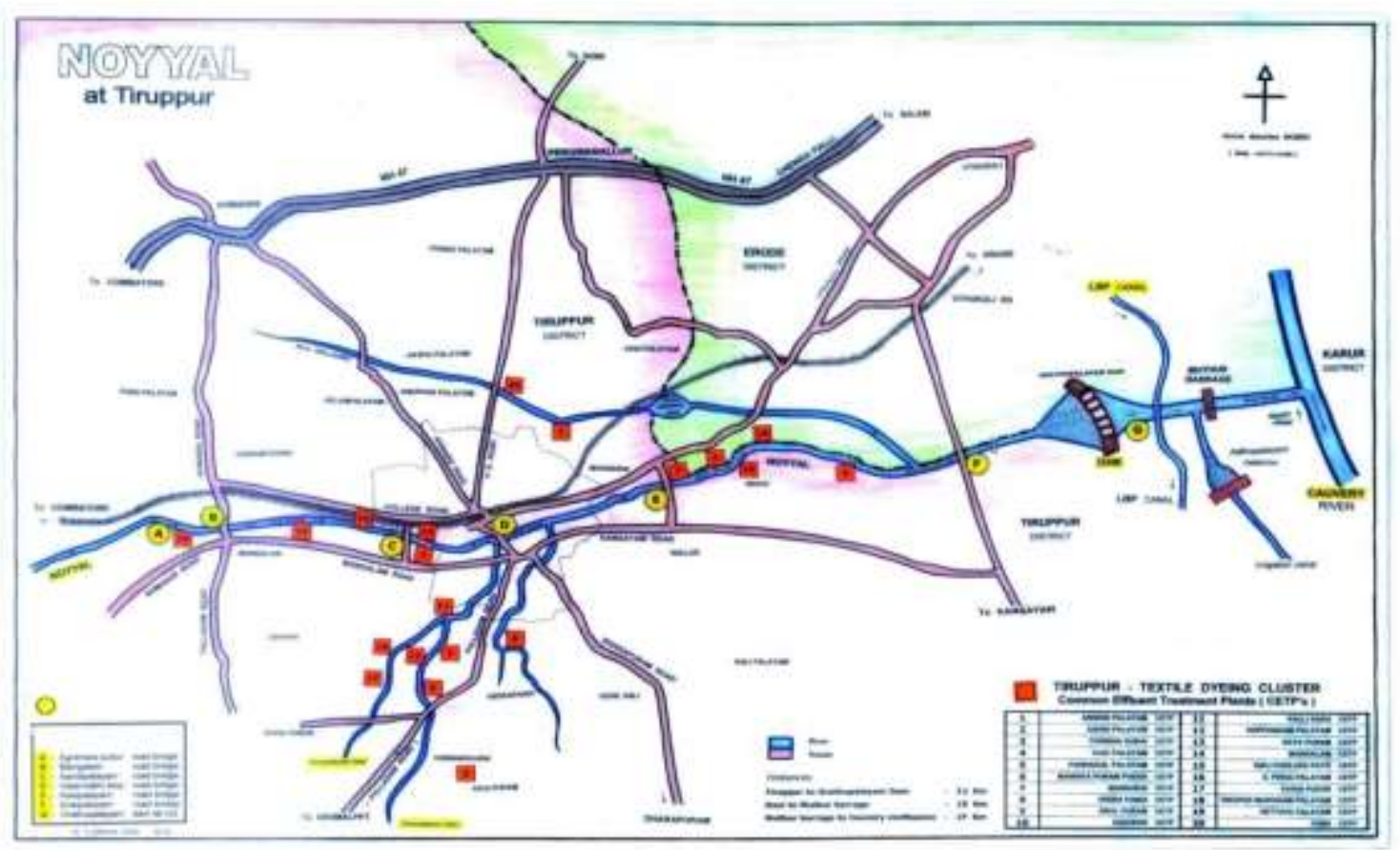

Source: Report on Assessment of Pollution from Textile Dyeing Units in Tirupur, Tamil Nadu and Measures Taken to Achieve Zero Liquid Discharge CENTRAL POLLUTION CONTROL BOARD ZONAL OFFICE (SOUTH), BENGALURU, 2014-15

The practice of discharging harmful effluents clandestinely in the neighbourhood has been well controlled due to CETPs and IETPs. The effluent after secondary treatment from the CETP is further treated in RO plant. The RO permeate is reused by the member units. The RO reject is concentrated in Multiple Effect Evaporator (MEE)/ Mechanical Vacuum Re-compressor (MVR). The concentrate is crystallized and centrifuged to recover salt. The salt recovered is reused. The liquid separated from the centrifuge is sent to solar evaporation pan. The salt thus collected in the solar pans is bagged and stored in secure land fill facility.

\section{Persisting Challenges}

Despite the above measures one of the most significant challenges that still persist for Tirupur today is water contamination. Textile production, particularly dyeing and bleaching, is water intensive 
and generates large quantities of effluent. Typical water consumption in Tirupur is around 200 to 400 litres $/ \mathrm{kg}$ of finished product, compared with the international norm of 120 to 150 litres $/ \mathrm{kg}$.[8] The city does not have a reliable piped water supply, and private water suppliers extract ground water and supply it to the textile industry using tankers. Ground water in neighbouring areas also has been decreasing and becoming contaminated. Lack of adequate water supply has inhibited growth and slowed down the flow of new investments.

\section{Sustainable production process and Marketing practice}

Though CETPs and IETPs are in place to treat effluents, still the damage caused to the groundwater and soil contamination in the river basin is yet to be restored. Likewise, there are also complaints that even after treatment the water contains heavy load of pollutants. The Tamil Nadu State Pollution Control Board has its offices in Coimbatore and Tirupur, and there are complaints that the Board is not effectively monitoring the water pollution. Environmentalists feel that nearly 90 percent of the garment units flout environmental regulations. [9] All this point to the fact that sooner or later the industry will have to transform to green production processes. Only this can offer a long-lasting solution to the situation.

Tirupur being an export hub is already familiar with eco labels and certifications. Technology wise also they have a competitive edge. The only hindrance for them to adopt green technology is the increased cost. Many environment friendly raw materials such as organic cotton and approved colours are more expensive. An Indian company has estimated that an Eco-Label t-shirt will be $15 \%$ more expensive to produce than an ordinary one. [10] This extra cost cannot be managed by small and medium sized producers in Tirupur. Therefore, new and innovative strategies are needed to offset the increased cost.

First, more R\&D facilities are needed in Tirupur to come out with cost effective and eco friendly dyeing methods. Textile industries all over the world are actively engaged in research to innovate improved methods of dyeing to reduce pollution. The surface of cotton fibers is negatively charged and doesn't readily react with negatively charged dye compounds. As a result, salts and alkali are added to the dye solution even then, only $75 \%$ of the dye is absorbed by cotton. [11] To ensure colorfastness, dyed fabric or yarn is washed over and over again in hot water, creating large amounts of wastewater. About $200 \mathrm{~L}$ of water is used to produce only $1 \mathrm{~kg}$ of fabric.[12] The wastewater thus let out contains high concentrations of dyes and chemicals, including chromium, arsenic, copper, and zinc.

To reduce this burden, Huntsman Corporation, an American MNC has developed a line of dyes for cotton called Avitera [13] that bonds to the fiber more readily. According to the company, the colors require one-quarter to one-third less water and one-third less energy. Another way to improve the bond between dyes and cotton fibers is a process called cationization. In North Carolina, textile industry 
veteran Tony Leonardis taking this approach. Leonard is the inventor and technical director behind ColorZen, a start-up that has developed a cotton pretreatment step. This pretreatment makes the dyeing process faster while using $90 \%$ less water, $75 \%$ less energy, and 90\% fewer auxiliary chemicals.[14] Many textile firms are turning to biology, using engineered microbes to reduce the use of chemicals in textile dyes. U.K.-based Colorifix and the French firm Pili claim microbes can produce highperformance; renewable dyes suitable for mainstream textiles [15]. This kind of research is not happening in Tirupur. Also, the textile units being small in size cannot afford to make any such investments into R\&D. Therefore, just like CETPs, the industry needs to set up R\&D facilities also jointly. Besides, government sponsored testing laboratories can also be located in Tirupur. Second, huge marketing efforts are needed from the supplier side. Increasing demand is a way to recover increased cost. The suppliers in Tirupur are not very strong in marketing. Majority does not have their own brands and they simply supply to established foreign brands. The industry must work towards developing a common brand - a green brand for their product. Having chains of retail showroom is the practice in European countries. As it is not possible for individual firms, the successful export firms together can also set up retail showrooms abroad. Once a successful brand name is created franchising strategy could also be adopted. The cluster has lot of institutional support and strong associations such as Tirupur Exporters Association (TEA), Textile Committee, Apparel Export Promotion Council (AEPC) etc. These associations can play a major role in setting up common R\&D facilities and developing a common brand for their cluster.

\section{Conclusion}

Tirupur being into exports for almost four decades is well aware of the significance of eco friendly practices to excel in the world market. The WTO regulations and the growing awareness on global warming have placed lot of constraints on regular methods of production. There is a compulsion now to switch over to greener production methods to retain their share in the global market. Though the cluster has lot of willingness to transform into a green cluster, there is reluctance because of cost and demand. Even though individual firms may find it difficult, the cluster can jointly take a bold step towards revamping its production and marketing practices. Exploring new markets and promoting green textiles would certainly give the cluster the first mover advantage which is very much essential to compete with strong rivals such as China.

\section{References:}

1. Chapter II profile of the study area - Shodhganga, shodhganga.inflibnet.ac.in > bitstream , 10603

2. Ibid 
3. 2014-15 "Report on Assessment Of Pollution From Textile Dyeing Units In Tirupur, Tamil Nadu And Measures Taken To Achieve Zero Liquid Discharge”, Central Pollution Control Board Zonal Office (South), Bengaluru.

4. Sumana Narayanan, 04 July 2015, Tirupur dyeing units told to close, Madras High Court orders shut down till zero discharge, https://www.downtoearth.org.in/news/tirupur-dyeing-unitstold-to-close-33025

5. $\mathrm{HC}$ orders closure of Tirupur dyeing units - The Economic Times, https://m.economictimes.com > ... > Cons. Products > Garments / Textiles

6. ibid

7. Tirupur was the first industrial cluster to implement ZLD in India www.indiantextilejournal.com $>$ News $>$ news=Tirupur-was-the-first-industri

8. Environmental Issues in Tirupur - South Asia Study Centre https://sites.google.com > site > sastudycentre > environmental-issues-in-tirupur

9. Latheef Kizhisseri and Pramod John, 2006, Multi-stakeholder Perspectives on Economic, Social and Environmental Issues in the Tirupur Garment Cluster Partners in Change, New Delhi and SolidaridadUtrecht, https://issuu.com/prakruthi/docs/knitted-together

10. Henning Høy Nygaard, 2015: Sustainable Textile Production Tirupur, India, Final report from a multi-stakeholder pilot implementation project in the Nordic countries and Tirupur, India, Nordic Council of Ministers, http://dx.doi.org/10.6027/TN2015-527

11. Melody M. Bomgardner, July 15, 2018, these new textile dyeing methods could make fashion more sustainable large and small suppliers vow to help a resource-intensive, costsensitive industry change with the times, c\&en Chemical and Engineering News, VOLUME

12. Ibid

13. Melody M. Bomgardnerop.cit

14. Melody M. Bomgardnerop.cit

15. Melody M. Bomgardnerop.cit 